International Journal of Pure and Applied Mathematics

Volume 107 No. 3 2016, 589-595

ISSN: 1311-8080 (printed version); ISSN: 1314-3395 (on-line version)

url: http://www.ijpam.eu

doi: 10.12732/ijpam.v107i3.7

\title{
MULTIVALUED CONTRACTIONS WITHOUT NORMALITY IN CONE $b$-METRIC SPACES
}

\author{
Anju Panwar ${ }^{1}$, Anita $^{2} \S$ \\ ${ }^{1,2}$ Department of Mathematics \\ Maharshi Dayanand University \\ Rohtak, 124001, Haryana, INDIA
}

\begin{abstract}
In this paper we prove fixed point theorem for multivalued mappings without the assumption of normality in cone $b$-metric spaces. The result not only directly improve some fixed point results in cone metric spaces and $b$-metric spaces, but also expand and generalize some previous results in cone metric spaces. We also give an example in support of the main result.
\end{abstract}

Key Words: cone $b$-metric spaces, non-normal cone, multivalued mapping and fixed points

\section{Introduction}

Huang and Zhang [4] introduced the concept of a cone metric space, replacing the set of the real numbers by an ordered Banach space and obtained some fixed point theorems for mappings satisfying different contractive conditions. Rezapour and Hamlbarani [9] presented the results of Huang and Zhang for the case of a cone metric space without normality in cone. Cho and Base [2] presented the result of [8] for multivalued mappings in cone metric spaces with normal cone. In 2011, Wardowski [10] introduced a new cone metric $H: N(X) \times N(X) \rightarrow E$, where $N(X)$ be the family of subset of $X$ and $(X, d)$ be a normal cone metric space. Jankovic et al. [7] has shown that the fixed

Received: October 5, 2015

Published: April 19, 2016

$\S_{\text {Correspondence author }}$ (c) 2016 Academic Publications, Ltd.

url: www.acadpubl.eu 
point problem in the setting of cone metric spaces is appropriate only in the case when the underlying cone is nonnormal, because the results concerning fixed points and other results in the case of cone metric spaces with nonnormal solid cones cannot be proved by reducing to metric spaces. Muhammad Arshad and Jamshaid Ahmad [1] proved the result of Wardowski [10] without the assumption of normality of cone.

The concept of $b$-metric space was introduced by Czerwik [3] in 1993 to extend the notion of metric space. Recently Hussain and Shah [6] introduced the notion of cone $b$-metric spaces as a generalization of $b$-metric and cone metric spaces. In this paper, we generalized the result of Muhammad Arshad and Jamshaid Ahmad [1] without the assumption of normality in cone $b$-metric spaces, for this we define $\mathrm{H}$-cone $b$-metric. We need the following definitions and results consistent with $[1,4,10]$.

Let $X$ and $Y$ be non empty sets. $T$ is said to be a multivalued mapping from $X$ to $Y$ if $T$ is a function from $X$ to the power set of $Y$. We denote a multivalued mapping by $X \rightarrow 2^{y}$.

A point $x \in X$ is said to be a fixed point of multivalued mapping $T$ if $x \in T x$. We denote the set of fixed points of $T$ by $\operatorname{Fix}(T)$.

Let $(X, d)$ be a metric space. Let $C B(X)$ denote the collection of non empty closed bounded subsets of $X$. For $A, B \in C B(X)$ and $x \in X$, define

$$
d(x, A)=\inf _{a \in A} d(x, a)
$$

and

$$
H(A, B)=\max \left\{\sup _{a \in A} d(a, B), \sup _{b \in B} d(b, A)\right\} .
$$

Note that $H$ is called the Hausdorff metric induced by the metric $d$.

Let $E$ be a real Banach space and $P$ be a subset of $E$. The subset $P$ is called cone if and only if:

(i) $P$ is closed, non empty and $P \neq\{0\}$;

(ii) $a, b \in R, a, b \geq 0$ and $x, y \in P \Rightarrow a x+b y \in P$;

(iii) $x \in P$ and $-x \in P \Rightarrow x=0$.

For a given cone $P \subseteq E$, we define a partial ordering $\leq$ with respect to $P$ by $x \leq y$ if and only if $y-x \in P$. We shall write $x<y$ to indicate that $x \leq y$ but $x \neq y$, while $x \ll y$ will stand for $y-x \in \operatorname{int} P$, where int $P$ denotes the interior of $P$. The cone $P$ is said to be solid if it has nonempty interior. The cone $P$ is called normal if there is a number $K>0$ such that for all $x, y \in E$, $0 \leq x \leq y$ implies $\|x\| \leq K\|y\|$. 
Definition $1.1([4])$. Let $X$ be a nonempty set. Suppose that the mapping $d: X \times X \rightarrow E$ satisfies :

(d1) $0<d(x, y)$ for all $x, y \in X$ with $x \neq y$ and $d(x, y)=0$ if and only if $x=y$;

(d2) $d(x, y)=d(y, x)$ for all $x, y \in X$;

(d3) $d(x, y) \leq d(x, z)+d(z, y)$ for all $x, y, z \in X$.

Then $d$ is called a cone metric on $X$ and $(X, d)$ is called a cone metric space.

Definition $1.2([6])$. Let $X$ be a nonempty set and $s \geq 1$ be a given real number. A mapping $d: X \times X \rightarrow E$ is said to be cone $b$-metric if and only if, for all $x, y, z \in X$, the following condition are satisfied :

(i) $0<d(x, y)$ for all $x, y \in X$ with $x \neq y$ and $d(x, y)=0$ if and only if $x=y$;

(ii) $d(x, y)=d(y, x)$ for all $x, y \in X$;

(iii) $d(x, y) \leq s[d(x, z)+d(z, y)]$ for all $x, y, z \in X$.

The pair $(X, d)$ is called a cone $b$-metric space.

Remark 1.3 ([6]). The class of cone $b$-metric spaces is larger than the class of cone metric spaces since any cone metric space must be a cone $b$-metric space. Therefore, it is obvious that cone $b$-metric spaces generalize $b$-metric spaces and cone metric spaces. We present a number of examples, as follows, which show that a cone $b$-metric spaces need not be a cone metric spaces.

Example $1.4([5])$. Let $E=R^{2}, P=\{(x, y) \in E: x, y \geq 0\} \subset E, X=R$ and $d: X \times X \rightarrow E$ such that $d(x, y)=\left(|x-y|^{p}, \alpha|x-y|^{p}\right)$, where $\alpha \geq 0$ and $p>1$ are two constants. Then $(X, d)$ is a cone $b$-metric space but not a cone metric space.

Example 1.5 ([5]). Let $X=\{1,2,3,4\}, E=R^{2}$, $P=\{(x, y) \in E: x \geq 0, y \geq 0\}$. Define $d: X \times X \rightarrow E$ by

$$
d(x, y)= \begin{cases}\left(|x-y|^{-1},|x-y|^{-1}\right) & \text { if } x \neq y \\ 0 & \text { if } x=y\end{cases}
$$

Then $(X, d)$ is a cone $b$-metric space with coefficient $s=\frac{6}{5}$. But it is not a cone metric space since the triangle inequality is not satisfied, because

$$
\begin{aligned}
& d(1,2)>d(1,4)+d(4,2), \\
& d(3,4)>d(3,1)+d(1,4) .
\end{aligned}
$$


Definition $1.6([6])$. Let $(X, d)$ be a cone $b$-metric space, $x \in X$ and $\left\{x_{n}\right\}$ be a sequence in $X$. Then

(i) $\left\{x_{n}\right\}$ converges to $x$ whenever for every $c \in E$ with $0 \ll c$ there is a natural number $n_{0}$ such that $d\left(x_{n}, x\right) \ll c$ for all $n \geq n_{0}$. We denote this by $\lim _{n \rightarrow \infty} x_{n}=x$;

(ii) $\left\{x_{n}\right\}$ is a Cauchy sequence whenever for every $c \in E$ with $0 \ll c$ there is a natural number $n_{0}$ such that $d\left(x_{n}, x_{m}\right) \ll c$ for all $n, m \geq n_{0}$;

(iii) $(X, d)$ is complete cone $b$-metric if every Cauchy sequence in $X$ is convergent.

Definition 1.7. Let $(X, d)$ be a cone $b$-metric space and $N(X)$ be a collection of nonempty subset of $X$. A mapping $H: N(X) \times N(X) \rightarrow E$ is called an $H$-cone $b$-metric on $N(X)$ induced by $d$ if the following condition hold:

(H1) $0 \leq H(A, B)$ for all $A, B \in N(X)$ with $A \neq B$ and $H(A, B)=0$ if and only if $A=B$;

(H2) $H(A, B)=H(B, A)$ for all $A, B \in N(X)$;

(H3) $H(A, B) \leq s[H(A, C)+H(C, B)]$ for all $A, B, C \in N(X)$.

(H4) If $A, B \in N(X), 0<\varepsilon \in E$ with $H(A, B)<\varepsilon$, then for each $a \in A$ there exist $b \in B$ such that $d(a, b)<\varepsilon$.

\section{Main Result}

Theorem 2.1. Let $(X, d)$ be a complete cone $b$-metric space with $s \geq 1$. Let $N(X)$ be a nonempty collection of nonempty closed subsets of $X$ and let $H: N(X) \times N(X) \rightarrow E$ be a $H$-cone $b$-metric on $N(X)$ induced by $d$. If for mapping $T: X \rightarrow N(X)$ there exist $\lambda \in(0,1)$ such that for all $x, y \in X$,

$$
H(T x, T y) \leq \lambda d(x, y)
$$

then $\operatorname{Fix} T \neq 0$.

Proof. Let $x_{0}$ be an arbitrary but fixed element of $X$ and $x_{1} \in T x_{0}$. If $x_{0}=x_{1}$, then $x_{0} \in \operatorname{Fix} T$, and if $x_{0} \neq x_{1}$, using the fact that

$$
H\left(T x_{0}, T x_{1}\right) \leq \lambda d\left(x_{0}, x_{1}\right)<\sqrt{\lambda} d\left(x_{0}, x_{1}\right)
$$


we may choose $x_{2} \in X$ such that $x_{2} \in T x_{1}$ and

$$
d\left(x_{1}, x_{2}\right)<\sqrt{\lambda} d\left(x_{0}, x_{1}\right)
$$

Similarly, in case $x_{1} \neq x_{2}$ we may choose $x_{3} \in X$ such that $x_{3} \in T x_{2}$ and

$$
d\left(x_{2}, x_{3}\right)<\sqrt{\lambda} d\left(x_{1}, x_{2}\right)<(\sqrt{\lambda})^{2} d\left(x_{0}, x_{1}\right)
$$

We can continue this process to find a sequence $\left\{x_{n}\right\}$ of points of $X$ such that

$$
\begin{aligned}
& x_{n+1} \in T x_{n} \text { for } n=0,1,2, \ldots \\
& \begin{aligned}
d\left(x_{n}, x_{n+1}\right) & <\sqrt{\lambda} d\left(x_{n-1}, x_{n}\right) \\
& <(\sqrt{\lambda})^{2} d\left(x_{n-2}, x_{n-1}\right)<\ldots<(\sqrt{\lambda})^{n} d\left(x_{0}, x_{1}\right) .
\end{aligned}
\end{aligned}
$$

Now for any $m>n$

$$
\begin{aligned}
d\left(x_{m}, x_{n}\right) \leq & s\left[d\left(x_{n}, x_{n+1}\right)+d\left(x_{n+1}, x_{m}\right)\right] \\
\leq & s d\left(x_{n}, x_{n+1}\right)+s^{2}\left[d\left(x_{n+1}, x_{n+2}\right)+d\left(x_{n+2}, x_{m}\right)\right] \\
\leq & \vdots \\
\leq & s d\left(x_{n}, x_{n+1}\right)+s^{2} d\left(x_{n+1}, x_{n+2}\right)+\ldots \\
& \quad+s^{m-n-1}\left[d\left(x_{m-2}, x_{m-1}\right)+d\left(x_{m-1}, x_{m}\right)\right] \\
\leq & s d\left(x_{n}, x_{n+1}\right)+s^{2} d\left(x_{n+1}, x_{n+2}\right)+\ldots \\
& \left.\quad+s^{m-n-1} d\left(x_{m-2}, x_{m-1}\right)+s^{m-n} d\left(x_{m-1}, x_{m}\right)\right] \\
\leq & s(\sqrt{\lambda})^{n} d\left(x_{0}, x_{1}\right)+s^{2}(\sqrt{\lambda})^{n+1} d\left(x_{0}, x_{1}\right)+\ldots \\
& \quad+s^{m-n}(\sqrt{\lambda})^{m-1} d\left(x_{0}, x_{1}\right) \\
\leq & s(\sqrt{\lambda})^{n}\left[1+s \sqrt{\lambda}+s^{2}(\sqrt{\lambda})^{2}+\ldots\right. \\
& \left.\quad+s^{m-n-1}(\sqrt{\lambda})^{m-n-1}\right] d\left(x_{0}, x_{1}\right) \\
\leq & {\left[\frac{s(\sqrt{\lambda})^{n}}{1-s \sqrt{\lambda}}\right] d\left(x_{0}, x_{1}\right) . }
\end{aligned}
$$

Let $0 \ll c$ be given. Choose a symmetric neighborhood $V$ of 0 such that $c+V \subseteq$ int $P$. Also, choose a natural number $N_{1}$ such that $\left[\frac{s(\sqrt{\lambda})^{n}}{1-s \sqrt{\lambda}}\right] d\left(x_{0}, x_{1}\right) \in V$, for all $n \geq N_{1}$. 
Then $\left[\frac{s(\sqrt{\lambda})^{n}}{1-s \sqrt{\lambda}}\right] d\left(x_{0}, x_{1}\right) \ll c$, for all $n \geq N_{1}$. Thus,

$$
d\left(x_{m}, x_{n}\right) \leq\left[\frac{s(\sqrt{\lambda})^{n}}{1-s \sqrt{\lambda}}\right] d\left(x_{0}, x_{1}\right) \ll c
$$

for all $m>n$. Therefore, $\left\{x_{n}\right\}_{n \geq 1}$ is a Cauchy sequence. Since $X$ is complete, there exists $u \in X$ such that $x_{n} \rightarrow u$. Since

$$
H\left(T x_{n}, T u\right) \leq \lambda d\left(x_{n}, u\right)<\sqrt{\lambda} d\left(x_{n}, u\right)
$$

for each $n, x_{n+1} \in T x_{n}$, we have $y_{n} \in T u$ such that $d\left(x_{n+1}, y_{n}\right)<\sqrt{\lambda} d\left(x_{n}, u\right)$.

Now, choose a natural number $N_{2}$ such that

$$
d\left(x_{n}, u\right) \ll \frac{c}{2}, \quad \text { for all } n \geq N_{2} .
$$

Then for all $n \geq N_{2}$,

$$
\begin{aligned}
d\left(u, y_{n}\right) & \leq d\left(u, x_{n+1}\right)+d\left(x_{n+1}, y_{n}\right) \\
& \leq d\left(u, x_{n+1}\right)+\sqrt{\lambda} d\left(x_{n}, u\right) \\
& \leq d\left(u, x_{n+1}\right)+d\left(x_{n}, u\right) \ll \frac{c}{2}+\frac{c}{2}=c .
\end{aligned}
$$

It follows that $y_{n} \rightarrow u$, and it implies that $u \in T u$.

Example 2.2. Suppose $X=[0,1], E=C_{R}^{2}[0,1]$ with the norm $\|x\|=$ $\|x\|+\left\|x^{\prime}\right\|_{\infty}, P=\{x \in E: x \geq 0\}, x(t)=t$ and $y(t)=t^{2 K}$. Then $0 \leq x \leq y$, $\|x\|=2$ and $\|y\|=1+2 K$. For all $K \geq 1$, since $K\|x\|<\|y\|$. Therefore, $P$ is non normal cone. Define $d: X \times X \rightarrow E$ as follows:

$$
(d(x, y))(t)=|x-y|^{p} e^{t}, \quad \text { for } p>1 .
$$

Then $(X, d)$ is a cone $b$-metric space but not a cone metric space. For $x, y, z \in$ $X$, set $u=x-z, v=z-y$, so $x-y=u+v$. From the inequality

$$
(a+b)^{p} \leq(2 \max \{a, b\})^{p} \leq 2^{p}\left(a^{p}+b^{p}\right) \text { for all } a, b \geq 0 .
$$

We have

$$
\begin{aligned}
|x-y|^{p} & =|u+v|^{p} \\
& \leq(|u|+|v|)^{p}
\end{aligned}
$$




$$
\begin{aligned}
& \leq 2^{p}\left(|u|^{p}+|v|^{p}\right) \\
& =2^{p}\left(|x-z|^{p}+|z-y|^{p}\right), \\
|x-y|^{p} e^{t} & \leq 2^{p}\left(|x-z|^{p} e^{t}+|z-y|^{p} e^{t}\right),
\end{aligned}
$$

which implies that $d(x, y) \leq s[d(x, z)+d(z, y)]$ with $s=2^{p}>1$. But

$$
|x-y|^{p} e^{t} \leq|x-z|^{p} e^{t}+|z-y|^{p} e^{t}
$$

is impossible for all $x>z>y$. Indeed, taking account of the inequality

$$
(a+b)^{p}>a^{p}+b^{p} \quad \text { for all } a, b>0,
$$

we have

$$
\begin{aligned}
& |x-y|^{p}>|x-z|^{p}+|z-y|^{p} \\
& |x-y|^{p} e^{t}>|x-z|^{p} e^{t}+|z-y|^{p} e^{t}
\end{aligned}
$$

for all $x>z>y$. Thus triangular inequality in cone metric is not satisfied, so $(X, d)$ is not a cone metric space but is a cone $b$-metric space.

Let $N(X)$ be a family of subset of $X$, $N(X)=\{[0, x]: x \in X\} \bigcup\{\{x\}: x \in X\}$, and define $H: N(X) \times N(X) \rightarrow E$ as follow

$$
H(A, B)= \begin{cases}|x-y|^{P} e^{t} & \text { for } A=[0, x], B=[0, y] \\ |x-y|^{P} e^{t} & \text { for } A=\{x\}, B=\{y\} \\ \max \left\{y^{p},|x-y|^{P}\right\} e^{t} & \text { for } A=[0, x], B=\{y\} \\ \max \left\{x^{p},|x-y|^{P}\right\} e^{t} & \text { for } A=\{x\}, B=[0, y]\end{cases}
$$

It is easy to observe that $H$ satisfies (H1)-(H4) of Definition 1.7.

Define $T: X \rightarrow N(X)$ as

$$
T x= \begin{cases}\{0\} & \text { for } x \in\left[0, \frac{1}{3}\right], \\ {\left[0, \frac{1}{3}\left(x-\frac{1}{3}\right)\right]} & \text { for } x \in\left(\frac{1}{3}, 1\right]\end{cases}
$$

Note that $T$ satisfies the condition of Theorem 2.1 with $\lambda=\frac{1}{3^{p}}$ and $0 \in \operatorname{Fix} T$. 


\section{References}

[1] M. Arshad, J. Ahamd, On multivalued contractions in cone metric spaces without normality, Journal of Hindawi Publishing Corporation, (2013), 1-3.

[2] S. Cho, J. Base, Fixed point theorems for multivalued maps in cone metric spaces, $J$. Fixed Point Theory Appl., 87 (2011), 1-7.

[3] S. Czerwik, Nonlinear set-valued contraction mappings in b-metric spaces, Atti Semin. Mat. Fis. Univ. Modena, 46 (1998), 263-276.

[4] L.G. Huang, X. Zhang, Cone metric spaces and fixed point theorems of contractive mappings, Journal of Mathematical Analysis and Applications, 332 (2007), 1468-1476.

[5] H. Huang, S. Xu, Fixed point theorems of contractive mappings in cone $b$-metric spaces and applications, Fixed Point Theory Appl., 112 (2013), 1-10.

[6] N. Hussain, M.H. Shah, KKM mappings in cone b-metric spaces, Comput. Math. Appl., 62 (2011), 1677-1684.

[7] S. Jankovic, Z. Kadelburg, S. Radenovic, On cone metric spaces a survey, Nonlinear Anal., 74 (2011), 2591-2601.

[8] N. Mizoguchi, W. Takahashi, Fixed point theorems for multivalued mappings on complete metric spaces, J. Math. Anal. Appl., 141 (1989), 177-188.

[9] S. Rezapour, R. Hamlbarani, Some notes on the paper cone metric spaces and fixed point theorems of contractive mappings, J. Math. Anal. Appl., 345 (2008), 719-724.

[10] D. Wardowski, On set-valued contractions of nadler type in cone metric spaces, Applied Mathematics Letters, 24 (3) (2011), 275-278. 